\title{
Adult onset xanthogranuloma - case report and review of literature
}

\author{
Liliana Gabriela Popa ${ }^{1,2}$, Mara Madalina Mihai ${ }^{1,2}$, Olguta Anca Orzann ${ }^{1,2}$, Cristina Beiu', \\ Tiberiu Tebeica ${ }^{3}$, Calin Giurcaneanu ${ }^{1,2}$ \\ ${ }^{1}$ Department of Oncologic Dermatology, "Elias" Emergency University Hospital, \\ "Carol Davila" University of Medicine and Pharmacy, Bucharest, Romania \\ 2Department of Dermatology, "Elias" Emergency University Hospital, Bucharest, Romania \\ ${ }^{3}$ Department of Pathology, Dr. Leventer Center, Bucharest, Romania
}

\begin{abstract}
Juvenile xanthogranuloma represents the most common form of non-Langerhans cell histiocytosis. It is tipically a childhood disorder, over $80 \%$ of cases developing in the first year of life. Adult onset xanthogranuloma is instead exceedingly rare; our literature research revealed a total number of only 35 cases reported to date. Cases with multiple cutaneous lesions occurring during adulthood are even rarer. The pathogenesis of the disease is incompletely understood and the possibility of extracutaneous involvement is uncertain. Although adult xanthogranulomatosis is not considered a paraneoplastic phenomenon, association with haematological malignancies is very frequent, therefore patients should be thoroughly investigated and closely monitored.

We report a case of multiple xanthogranulomas developing in an otherwise healthy adult female patient and review the literature regarding this uncommon disease.
\end{abstract}

Keywords: xanthogranuloma, non-Langerhans cell histiocytosis

\section{INTRODUCTION}

Juvenile xanthogranuloma (JXG) represents the most common type of non-Langerhans cell histiocytosis $(1,2)$. It is a benign, usually self-limited histiocytic disorder thatmainly manifests as a solitary red, orange, yellow, or brown cutaneous papule or nodule. Multiple skin lesions occur in approximately $10 \%$ of cases $(3,4)$. The eyes, skull, and viscera can also be involved, but extracutaneous JXG is very infrequent. In the vast majority of cases thelesions develop during early childhood (5).

Adult onset xanthogranuloma is exceedingly rare, only 35 cases having been reported so far (6). Patients with multiple cutaneous lesions occurring during adulthood are even rarer.

We report a case of multiple xanthogranulomas developing in an otherwise healthy adult female patient and review the literature regarding this uncommon disease.

\section{CASE REPORT}

A 29-year-old woman with no relevant personal or family medical history was referred to our clinic for the presence of multiple asymptomatic well defined, dome-shaped, firm to elastic, smooth surfaced, orange papules and nodules 0.5 to $2 \mathrm{~cm}$ in diameter, distributed on the face, neck, trunk and limbs (Fig. 1). Under dermoscopy, we observed yellow-orange structureless lesions, some with an erythematous halo with fine telangiectasias (Fig. 2). The skin lesions first appeared 7 years previously and gradually grew in size and number. The rest of the physical examination did not reveal pathologic findings.

The clinical diagnosis of XG was confirmed by the histopathologic examination of an excisional skin biopsy that showed a fibrohistiocytic proliferation located in the upper dermis that included giant, multinucleated Touton cells, accompanied by 


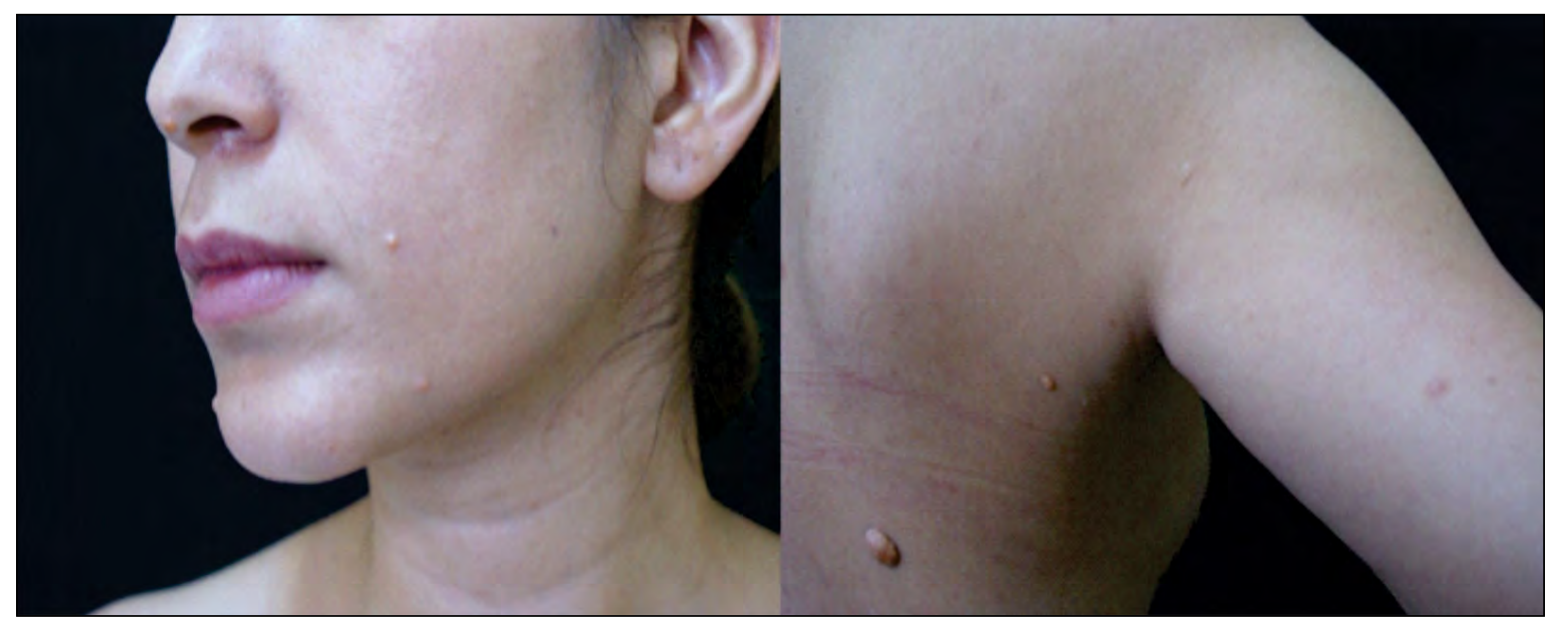

FIGURE 1. Multiple orange papules and nodules of different sizes, ranging from 0.5 to $2 \mathrm{~cm}$ located on the trunk, limbs and face

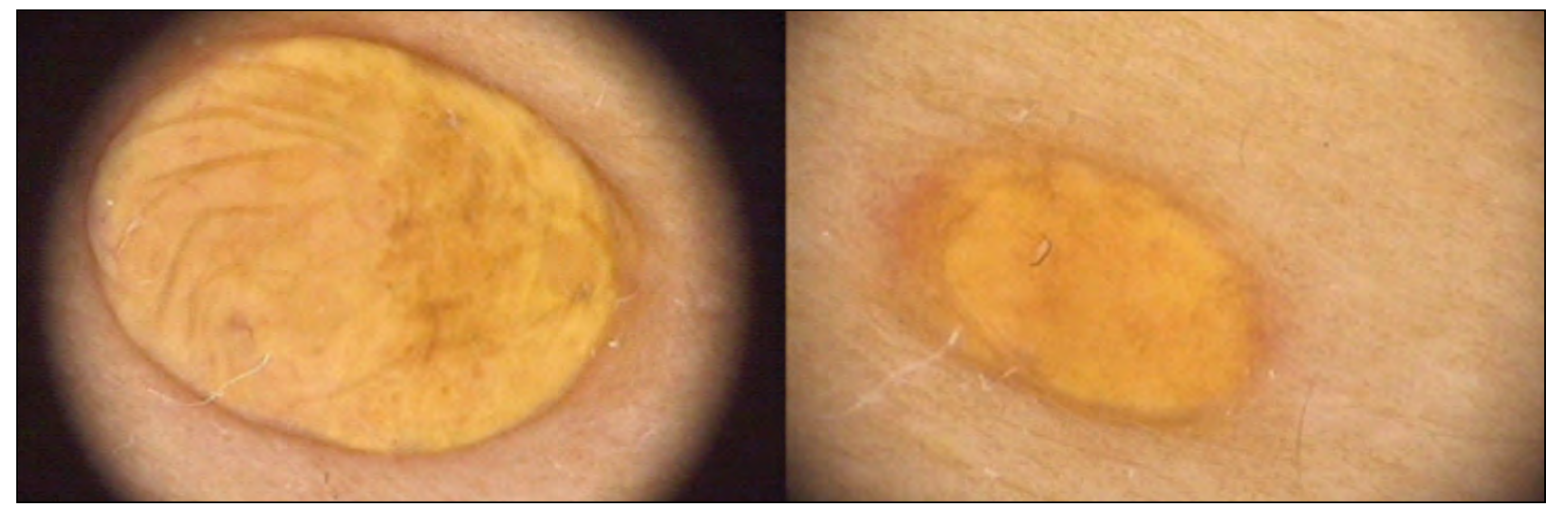

FIGURE 2. Dermoscopy revealed yellow-orange structureless lesions, some with a faint erythematous halo

an infiltrate of lymphocytes and rare eosinophils (Fig. 3).

Laboratory test results were all within normal limits. No visceral involvement was evident on abdominal and pelvic ultrasound. The patient was also thoroughly examined by an experienced ophthalmologist who detected no abnormalities.

Given the absence of cutaneous symptoms and extracutaneous lesions, the benign nature of the condition and the lack of efficient systemic therapies, we decided to prescribe no treatment and to monitor our patient biannually.

\section{DISCUSSION}

Gartmann and Tritsch published the first case report of adult onset XG in 1963 (7), more than half a century after the initial description of JXG byAdamson, in 1905. JXG is a rare condition, accounting for approximately $0.5 \%$ of pediatric tumors (8). Xanthogranuloma is typically a childhood disease, over $80 \%$ of cases developing in the first year of life (3). Roughly $10 \%$ of cases occur in adults, es- pecially during the third or fourth decade of life( 9 , 10). Although JXG is slightly more common in males, adult onset XG equally affects both sexes. It does not present any racial predilection (11).

The etiology of the disease has not been elucidated. No genetic predisposition has been identified in patients with solitary cutaneous JXG, nor has familial clustering been observed (12). JXG with systemic involvement, on the other hand, seems to be linked to mutations of the MAPK pathway genes (13). Similar to other non-Langerhans cell histiocytoses, $\mathrm{XG}$ originates in $\mathrm{CD}_{1} 4^{+}$dermal or interstitial dendrocytes $(14,15)$. An aberrant response of histiocytes to yet unknown stimuli, most probably physical or infectious is suspected to be the underlying mechanism of the disease, the ensuing foreign body-type reaction leading to the appearance of cutaneous and/or extracutaneous lesions $(16,17)$. Other proposed triggers for the granulomatous reaction are complexes of serum immunoglobulins and lipids or the binding of monoclonal proteins to lipoprotein receptors on monocytes $(18,19)$. 


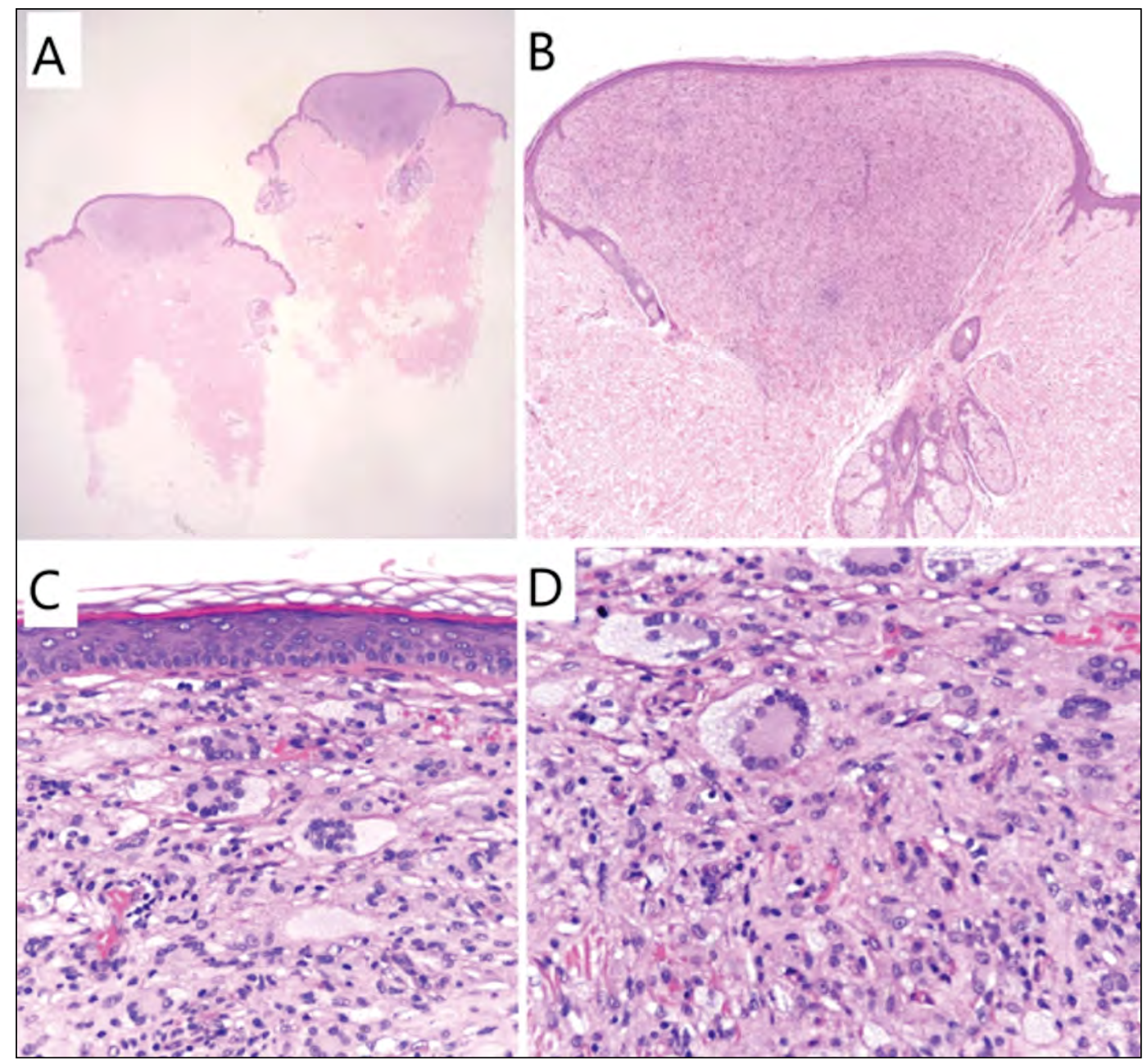

FIGURE 3. Histopathology showing a dense histiocytic infiltrate in the upper dermis that includes giant cells, accompanied by an infiltrate of lymphocytes and rare eosinophils (haematoxylin and eosin, A. x20, B. x40, C. x200, D. x200)

JXG has been described in association with a series of diseases, such as neurofibromatosis type 1 (NF1), Niemann-Pick disease, juvenile myelomonocytic leukemia (JMML), and urticaria pigmentosa (20-22). The link between JXG and adult onset xanthogranuloma and hematological malignancies is indisputable $(6,10)$. Among the 35 cases of xanthogranuloma occurring in adults reported in the literature, 4 were associated with leukemias, 3 with lymphomas, 1 with myelodysplastic syndrome, 1 with hypereosinophilic myelodysplasia, 1 with a monoclonal gammapathy, and 1 with essential thrombocythemia (6). Only one case report of adult onset eruptive xanthogranuloma arising in a patient with a solid tumor (gastrointestinal stromal tumor) has been published (23). Cutaneous xanthogranulomas do not always regress following treatment for the coexisting neoplasia, therefore they cannot be viewed as paraneoplastic phenomena $(24,25)$.

JXG manifests as asymptomatic red, orange, yellow, or brown, firm or rubbery, smooth cutaneous papules or nodules, with a diameter of $0.5-2 \mathrm{~cm}$
(22). The clinical forms of xanthogranuloma comprise the small nodular/papular form $(0.2-0.5 \mathrm{~cm})$, the large nodular form $(0.5-2 \mathrm{~cm})$, and the giant $X G$ $(>2 \mathrm{~cm})$ (26). Mixed, subcutaneous or plaque forms have also been described.The lesions are more often encountered in the head and neck region or on the upper trunk, but can be located in any areaof the body except the palms, soles and mucous membranes (22). Up to $90 \%$ of patients present a single lesion (4). Multiple skin lesions are usually seen in infants younger than 6 months (27) and are exceptionally rare in adults (6). Moreover, multiple adult xanthogranulomas are much more frequent in men than women, with a male/female ratio of $12: 1$ $(4,22)$. Our patient presented a mixed form of xanthogranulomatosis, with numerous, widely distributed skin lesions of various sizes.

JXG lesions generally resolve spontaneously. However, this is not the case with adult xanthogranuloma $(5,16)$.

Extracutaneous xanthogranuloma is encountered in $4-5 \%$ of patients ( 8 ) and can affect any or- 
gan or system (28). Only half of the patients with systemic JXG present cutaneous lesions (29). Nevertheless, systemic involvement is more frequently seen in children younger than 2 years with multiple skin lesions (27).

The most common extracutaneous site is the eye, particularly the iris and the eyelids (22). Xanthogranulomas located in the posterior pole or orbits are extremely rare. Ocular involvement is usually unilateral and closely resembles skin lesions, which they either precede, or follow. Conjunctivitis, uveitis, heterochromia iridis, iris masses, hyphema with secondary glaucoma, amblyopia, diplopia, retinal detachment, keratitis, scleritis, episcleritis, or blepharoptosis are manifestations of the ocular xanthogranuloma $(30,31)$.

The lung, myocardium, pericardium, liver, spleen, gastro-intestinal tract, kidney, adrenal gland, testes, ovaries, skeletal muscles, periosteum, bone marrow, salivary glands, lacrimal glands, paranasal sinuses, larynx, retroperitoneum, as well as the central nervous system have been reported to harbor xanthogranulomas in children (32).

While no case of adult onset xanthogranuloma with concomitant cutaneous and extracutaneous lesions has been reported, cases of solitary extracutaneous xanthogranulomas located in the breast (33), eye (34), and central nervous system (35) without coexisting skin lesions have been described.

Spontaneous involution with residual hyperpigmentation or atrophic scars is the expected course of skin, ocular or internal JXG lesions (25), but it is unlikely in adult xanthogranuloma (36).

The diagnosis is established based on the clinical picture. Histopathologic examination is useful for the differentiation from other non-Langerhans and Langerhans cell histiocytoses, xanthoma, mastocytoma, Spitz nevus, neurofibroma, dermatofibroma granuloma annulare, and sarcoidosis, and in older patients with multiple skin lesions xanthoma disseminatum and eruptive xanthoma.

The histopathologic features of adult onset xanthogranuloma are identical to those of JXG and consist of a well circumscribed, non-encapsulated lesion located in the dermis and upper part of the hypodermis composed mainly of histiocytes and spindle cells in early stages and foamy, lipid-laden, vacuolated histiocytes and multinucleated giant cells, including Touton giant cells in mature lesions $(22,27)$. A perivascular and interstitialmixed infiltrate of lymphocytes, eosinophils, neutrophils, and mast cells is also present. As they regress, the le- sions become fibrotic $(22,29)$. The overlying epidermis is either normal or thinned, occasionally ulcerated $(22,29)$.

Immunohistochemistry aids in establishing the definitive diagnosis as the lesions arepositive for histiocytic markers such as factor XIIIa, CD68, CD163, CD14, and also for fascin, and negative for $\mathrm{S} 100$ and CD1 a, which differentiate them from Langerhans cell histiocytoses (22).

Routine laboratory tests are recommended in order to exclude metabolic or haematologic disorders.

Ocular ultrasound and anterior-segment optical coherence tomography are useful tools for the accurate localization of ocular lesions. Anterior chamber paracentesis and fine-needle aspiration biopsy may be performed when the diagnosis is uncertain, especially in the absence of characteristic skin lesions.

Treatment is not necessary for solitary skin lesions. Surgical excision is only practiced for diagnosis or cosmesis. Several treatments have been tried with modest results in cases with numerous cutaneous xanthogranulomas. These include systemic or intralesional steroids, oral retinoids, thalidomide, cryotherapy, $\mathrm{CO}_{2}$ laser treatment $(6,37$, 38).

On the contrary, prompt diagnosis and aggressive treatment are crucial for vision preservation in patients with ocular involvement. Topical, subconjunctival, intralesional, or systemic glucocorticoids are the first line treatment. Radiotherapy and surgical intervention are usually reserved for refractory cases (39). Visceral xanthogranuloma also require excision, radiotherapy and/or cytotoxic therapy (40).

\section{CONCLUSIONS}

Although very uncommon, adult onset xanthogranuloma should be considered in the differential diagnosis of single or multiple cutaneous red-orange papules or nodules. Due to its rarity, the pathogenesis of the disease is poorly understood and the possibility of extracutaneous involvement is uncertain. Most cases have a very good prognosis. Nevertheless, patients should be informed on the risk of ocular or systemic disease and should be closely monitored.

\section{Acknowledgement}

The first two authors contributed equally. 


\section{REFERENCES}

1. Höck $M, Z$ Zelger B, Schweigmann $G$ et al. The various clinical spectra of juvenile xanthogranuloma: Imaging for two case reports and review of the literature. BMC Pediatr. 2019;19:128.

2. Cichewicz A, Białecka A, Męcińska-Jundziłł $K$ et al. Congenital multiple juvenile xanthogranuloma. Postepy. Dermatol. Alergol. 2019; 36:365-368.

3. Nayak S, Acharjya B, Devi B, Patra MK. Multiple xanthogranulomas in an adult. Indian J. Dermatol. Venereol. Leprol. 2008;74:67-68.

4. Saad N, Skowron F, Dalle S et al. Multiple adult xanthogranuloma: Case report and literature review. Dermatology. 2006;212:73-76.

5. Rodriguez J, Ackerman AB. Xanthogranuloma in adults. Arch. Dermatol. 1976;112:43-44.

6. Debois D, Marot L, Andre M, Dachelet C. Thalidomide as an effective treatment for adult multiple xanthogranuloma. JAAD Case Rep. 2018:4:896-898.

7. Gartmann $\mathrm{H}$, Tritsch $\mathrm{H}$. Heln- and grobknotigens Naevoxanthoendotheliom. Dermatologica. 1963;215:409-421.

8. Janssen D, Harms D. Juvenile xanthogranuloma in childhood and adolescence: a clinicopathologic study of 129 patients from the kiel pediatric tumor registry. Am. J. Surg. Pathol. 2005;29:21-28.

9. Redbord KP, Sheth AP. Multiple juvenile xanthogranulomas in a 13-year-old. Pediatr. Dermatol. 2007;24:238-240.

10. Achar A, Naskar B, Mondal PC, Pal M. Multiple generalized xanthogranuloma in adult: Case report and treatment. Indian J. Dermatol. 2011;56:197-199.

11. Winkelmann RK. Cutaneous syndromes of non-X histiocytosis: A review of the macrophage histiocyte diseases of the skin. Arch. Dermatol. 1981;117:667-672.

12. Paxton CN, O'Malley DP, Bellizzi AM et al. Genetic evaluation of juvenile xanthogranuloma: genomic abnormalities are uncommon in solitary lesions, advanced cases may show more complexity. Mod. Pathol. 2017;30:1234-1240.

13. Diamond EL, Durham BH, Haroche J et al. Diverse and Targetable Kinase Alterations Drive Histiocytic Neoplasms. Cancer Discov. 2016; 6:154-165.

14. Weitzman S, Jaffe R. Uncommon histiocytic disorders: the nonLangerhans cell histiocytoses. Pediatr. Blood Cancer 2005; 45:256-264.

15. Caputo R, Marzano AV, Passoni E, Berti E. Unusual variants of non-Langerhans cell histiocytoses. J. Am. Acad. Dermatol. 2007; 57:1031-1045.

16. Sueki H, Saito T, lijima M, Fujisawa R. Adult-onset xanthogranuloma appearing symmetrically on the ear lobes. J. Am. Acad. Dermatol. 1995;32:372-374.

17. Balfour HH, Speicher CE, McReynolds DG. Juvenile xanthogranuloma associated with cytomegalovirus infection. Am. J. Med. 1971; 50:380-383.

18. Higgins LS, Go RS, Dingli D et al. Clinical features and treatment outcomes of patients with necrobiotic xanthogranuloma associated with monoclonal gammopathies. Clin. Lymphoma Myeloma Leuk. 2016;16:447-452.

19. Fernández-Herrera J, Pedraz J. Necrobioticxanthogranuloma. Semin. Cutan. Med. Surg. 2007;26:108-113.

20. Fenot M, Stalder JF, Barbarot S. Juvenile xanthogranulomas are highly prevalent but transient in young children with neurofibromatosis type 1. J. Am. Acad.Dermatol. 2014;71:389-390.
21. Shin HT, Harris MB, Orlow SJ. Juvenile myelomonocytic leukemia presenting with features of hemophagocyticlymphohistiocytosis in association with neurofibromatosis and juvenile xanthogranulomas. J. Pediatr. Hematol. Oncol. 2004;26:591-595.

22. Monahan SH. Dermatologic Manifestations of Juvenile Xanthogranuloma.[Internet] available at https://emedicine.medscape. com/article/1111629-overview,

23. Vadeboncoeur S, Provost N. Multiple xanthogranulomas in an adult. J.Cutan. Med. Surg. 2016;20:474-477.

24. Chiou CC, Wang PN, Yang LC, Kuo TT, Hong HS. Disseminated xanthogranulomas associated with adult T-cell leukaemia/lymphoma: A case report and review the association of haematologic malignancies. J. Eur. Acad. Dermatol. Venereol. 2007;21:532-535.

25. Shoo BA, Shinkai K, McCalmont TH, Fox LP. Xanthogranulomas associated with hematologic malignancy in adulthood. J. Am. Acad. Dermatol. 2008;59:488-493.

26. Caputo R, Grimalt R, Gelmetti C, Cottoni F. Unusual aspects of juvenile xanthogranuloma. J. Am. Acad. Dermatol. 1993;29:868-870.

27. Cypel TK, Zuker RM. Juvenile xanthogranuloma: Case report and review of the literature. Can. J. Plast. Surg. 2008;16:175-177.

28. Meshkini A, Shahzadi S, Zali A et al. Systemic juvenile xanthogranuloma with multiple central nervous system lesions. J. Cancer Res. Ther. 2012;8:311-313.

29. Hernandez-Martin A, Baselga E, Drolet BA, Esterly NB. Juvenile xanthogranuloma. J. Am. Acad.Dermatol. 1997;36:355-367.

30. Lau HH, Yip WW, Lee A et al. Three different ophthalmic presentations of juvenile xanthogranuloma. Hong Kong Med. J. 2014;20:261-263.

31. Samara WA, Khoo CT, Say EA et al. Juvenile Xanthogranuloma Involving the Eye and Ocular Adnexa: Tumor Control, Visual Outcomes, and Globe Salvage in 30 Patients. Ophthalmology. 2015; 122:2130-2138.

32. Webster SB, Reister HC, Harman LE Jr. Juvenile xanthogranuloma with extracutaneous lesions. A case report and review of the literature. Arch. Dermatol. 1966;93:71-76.

33. Hwang SH, Son EJ, Oh KK et al. Bilateral xanthogranuloma of the breast: Radiologic findings and pathologic correlation. J. Ultrasound Med. 2007;26:535-537.

34. Parmley VC, George DP, Fannin LA. Juvenile xanthogranuloma of the iris in an adult. Arch. Ophthalmol. 1998;116:377-379.

35. Miranda P, Lobato RD, Ricoy JR et al. Xanthogranuloma of the choroid plexus of the third ventricle: Case report and literature review. Neurocirugia (Astur) 2005;16:518-522.

36. Chang SE, Cho S, Choi JC et al. Clinicohistopathologic comparison of adult type and juvenile type xanthogranulomas in Korea. J.Dermatol. 2001; 28:413-418.

37. Pehr K, Elie J, Watters AK. Juvenile xanthogranuloma in a 77-year-old man. Int. J.Dermatol. 1994;33:438-441.

38. Tan LC, Tan KB, Aw CW. Unusual presentation of adult xanthogranuloma. Singapore Med. J. 2014;55:e25-e27.

39. Kontos G, Borooah S, Khan A et al. The epidemiology, clinical characteristics, histopathology and management of juvenile- and adult-onset corneoscleral limbus xanthogranuloma. Graefes Arch. Clin. Exp. Ophthalmol. 2016;254:413-420.

40. Puttgen KB, Juvenile xanthogranuloma (JXG) [Internet] available at https://www.uptodate.com/contents/juvenile-xanthogranuloma-jxg. 